REVIEW

\title{
Epidemiology of low back pain in children and adolescents
}

\author{
G T Jones, G J Macfarlane
}

Arch Dis Child 2005;90:312-316. doi: 10.1136/adc.2004.056812

It has been estimated that over $80 \%$ of the population will report low back pain (LBP) at some point in life,' and each year $7 \%$ of the adult population consult their GP with symptoms. ${ }^{2}$ Prevalence increases with age, reaching a peak during the sixth decade of life. ${ }^{3}$ Until recently little was known about LBP at young ages. Clinically it was perceived to be uncommon - with few children consulting because of LBP in primary care. Large prospective epidemiological studies have shown that, in those free of LBP at baseline, the best predictor of future onset is a previous history of LBP. ${ }^{4}$ Therefore, to understand the epidemiology of LBP, and what predisposes someone to a trajectory of LBP in adult life, it is important to examine the condition at young ages, to determine factors responsible for onset of initial episodes, and to examine whether LBP in childhood is related to symptoms in adulthood.

See end of article for authors' affiliations

Correspondence to: Dr G T Jones, ARC Epidemiology Unit, Division of Epidemiology and Health Sciences, The University of Manchester Stopford Building, Oxford Road, Manchester M13 9PT, UK; gareth.jones@ manchester.ac.uk

Accepted 7 October 2004
A structured search of Medline (July 2004) revealed that there have been relatively few large epidemiological studies conducted investigating the occurrence and aetiology of low back pain (LBP) in children. This article reviews evidence from the initial studies in this area, summarises the emerging evidence, and identifies areas for future study.

\section{OCCURRENCE}

Estimates of LBP prevalence in children and adolescents vary widely between studies depending on the age of study participants, and on methodological differences-particularly in terms of LBP definition. Watson et al report a one month period prevalence of $24 \%$ in schoolchildren aged 11-14 years in northwest England, ${ }^{5}$ whereas Balagué et al show the one year prevalence to be $26 \%$ in schoolchildren aged 12-17 years in Switzerland. ${ }^{6}$ Salminen et al show the one year prevalence of LBP "with limitation to activity" to be $17.6 \%$ in 14 year old Finnish children $;^{7}$ also in Finland, Taimela et al report a prevalence of $18 \%$, using the same definition. ${ }^{8}$ Even studies that record pain over a very short time interval (for example, point prevalence) reveal that as many as 1 child in 20 may be suffering from LBP at any one time..$^{9-11}$ As in adults, prevalence of LBP in childhood increases with age and has been shown repeatedly to be higher in girls than in boys. ${ }^{9^{12-14}}$

Although it is difficult to measure LBP incidence, studies have shown that "new onset" LBP is also common. A recent study revealed that $19 \%$ of children aged 11-14 years, and known to be free of symptoms at baseline, reported LBP 12 months subsequently. ${ }^{15}$ Other authors have presented similar results with $16 \%, 22 \%$, and $22 \%$ of 8,11 , and 13 year olds, respectively, reporting new onset LBP two years after initial assessment. ${ }^{16}$

Some authors have reported that self-reported LBP related disability in childhood is also common. Watson et al reported that, in a large community study, $94 \%$ of symptomatic children aged 11-14 years reported difficulty with one or more of the activities listed in a modified version of the Hannover Functional Ability Questionnaire; ${ }^{5}$ these activities included reaching up to a high shelf; sitting up in bed from a lying position; and bending down to put on socks. However, using a similar disability instrument, Salminen et al reported limitations in only $18 \%$ of individuals. ${ }^{7}$ Despite being reported as a common and often limiting experience, few children report LBP sufficient enough to prevent them from attending school or playing sports. ${ }^{8} 1017$

Consultations for LBP are also uncommon. ${ }^{5} 917$ Turner et al reported that of children referred with back pain to the department of orthopaedic surgery at a large children's hospital in the UK, spondylolysis was diagnosed in $13 \%$ of the individuals. Infection, tumour, and disc prolapse was reported in $8 \%, 6 \%$, and $6 \%$ of cases, respectively, and no specific cause was found in approximately half of cases. ${ }^{18}$ Common imaging techniques have proved to be poor at distinguishing between adolescents with and without LBP. Harreby et al showed in the community that 13\% of 14 year old schoolchildren had radiological abnormalities of the spine-the majority being Scheuermann's changes-but was unable to discriminate between LBP and non-LBP subjects in this way. ${ }^{19}$ Similarly, using magnetic resonance imaging, other authors have shown that while disc protrusion is more common in cases (children with LBP) than in controls, there are no significant differences between groups in terms of Scheuermann-type changes, transitional vertebra, and disc space narrowing. ${ }^{20}$

In summary, LBP is a common condition in childhood and, while it can be associated with serious pathology, this is rare and, for the majority, symptoms are mild, non-specific, and self-limiting. Although self-reported limitation is common, symptoms rarely result in consultation. Even among those consulting to family physicians, most will not have an organic cause identified.

\section{AETIOLOGY}

Most of the work on the aetiology of LBP in childhood and adolescence has been undertaken during the past decade. Although many studies purport to determine risk factors, the majority of previous work has been cross sectional in nature 
and has been unable, therefore, to address the temporal nature of any relation between exposure and outcome. As such, these studies can only truly identify features associated with LBP, rather than risk factors (or markers) for its development.

Studies of factors associated with the occurrence of LBP in youth fall into four main categories: anthropometry, lifestyle factors, mechanical load (principally schoolbag carriage), and the role of psychological, social, and behavioural factors.

\section{Anthropometry}

\section{Height}

A number of authors have examined the association between LBP and child height. Fairbank et al showed a significantly increased sitting height (height minus leg length) in school pupils aged 13-17 years with a history of LBP, compared with those free of pain, although the relation with standing height proved inconclusive. ${ }^{21}$ Others have noted an association in boys but not in girls. ${ }^{22-24}$ Prospectively, however, a number of studies have shown that child height at baseline does not predict the future occurrence of LBP. ${ }^{25}$

Rather than height per se, it has been postulated that LBP may result from differential growth rates between the vertebrae and the surrounding muscle and ligamentous tissue, ${ }^{26}$ and this muscle imbalance may increase the likelihood of pain in this area. In support of this, some authors have pointed out that the onset of LBP roughly corresponds with the adolescent growth spurt, and that those with a high growth spurt $(>5 \mathrm{~cm}$ in six months) are three times more likely to report LBP than their peers. ${ }^{27}$ Balagué et al, however, showed no association between LBP and trunk muscle weakness, ${ }^{27 a}$ and others have shown no difference in growth between those reporting and those not reporting LBP..$^{25}$

Spinal mobility is often thought to be associated with LBP, but overall there is relatively little evidence to support this. Harreby et al report that hyper-mobility is associated cross sectionally with severe LBP, but they report no association with non-severe LBP. ${ }^{28}$ Prospectively, little work has been conducted. In a longitudinal study of 98 children in Finland, Kujala et al state that low maximal lumbar flexion in boys, and extension in girls, is associated with the onset of LBP, ${ }^{25}$ but the evidence is weak.

\section{Weight/body mass index}

A number of authors have examined the association between LBP and child weight and/or body mass index (BMI). Some commentators have pointed out, however, that BMI is age related and should be interpreted with care in children-if it ought to be used at all. Nonetheless, providing caution is observed, BMI is probably the quickest and easiest measure of obesity and, for these reasons, is very convenient in large scale epidemiological studies. Cross sectionally, several authors have reported no significant differences in weight and/or BMI between children with and without LBP, ${ }^{13} 2429$ whereas others have found that those reporting LBP are heavier. ${ }^{21}$ Little work has been done of a prospective nature. Salminen et al found that while weight at follow up was greater in those with recurrent or continuous LBP, baseline weight was not predictive of future pain. ${ }^{23}$ Similarly, Nissinen et al showed that baseline weight was not significantly associated with an incident episode of LBP over the subsequent 12 months. ${ }^{22}$

Overall therefore, while there is some evidence that children with LBP may be heavier, there is little evidence to suggest that height, growth, weight, or BMI are associated with the onset of LBP symptoms.

\section{Lifestyle factors}

Physical activity

An increased frequency of radiological abnormalities has been observed in the spine of young athletes, with a greater frequency associated with particular sports: weightlifting and body building; ${ }^{30}$ gymnastics; ${ }^{31}$ rowing $;{ }^{26}{ }^{30}$ and golf and racket sports. $^{30}{ }^{32}$ Poor trunk muscle strength and decreased trunk muscle endurance have been reported to be associated with LBP by some, but not all, authors, ${ }^{24} 2633$ although whether or not this is related to physical activity is unclear: Sjolie showed no correlation between regular physical activity and low back strength. ${ }^{34}$

A number of other authors have referred to the J-shaped curve relation of physical activity and LBP-where moderate levels of activity are associated with a general conditioning effect, increased trunk muscle tone, the prevention of hyperflexion/extension and associated trauma, and a concomitant decrease in the risk of LBP. In contrast, higher levels of activity may be associated with over-training, insufficient recovery between activities, greater exposure to injury, and thus an increased occurrence of LBP. ${ }^{8}{ }^{12}{ }^{29}$ In addition, several studies have shown an increase in the occurrence of LBP associated with sporting activities at a competitive level. ${ }^{35} 36$

Much of the epidemiological evidence in this field is cross sectional and cannot adequately address the issue of cause and effect. Prospectively, however, Salminen et al reported that physical activity at baseline "was not predictive" of back pain at follow up, ${ }^{23}$ and others have also been unable to show consistent increases in the risk of new onset LBP associated with prior levels of physical activity. ${ }^{15}$

\section{Sedentary activity}

Few authors have studied the effects of regular or prolonged sedentary activity on the occurrence of LBP. Some have found that children who play video games for more than two hours per day report more LBP than other children, ${ }^{37}$ but show inconsistencies, in that the same is not true for watching television for the same period of time. Balagué et al showed that children who watch a small amount of television per day $(<1$ hour) were at no greater or lesser risk of back pain than those who watched none, ${ }^{36}$ whereas watching $1-2$ hours, and watching $>2$ hours were associated with a $70 \%$ and a $210 \%$ increase in the odds of LBP, respectively. Other studies have shown similar results. ${ }^{14}$

However, all of the above papers report cross sectional results and it is impossible, therefore, to examine whether the sedentary activities are precursors, or consequences, of back pain. Jones et al examined the relation between sedentary activity and LBP prospectively, and showed no association between sedentary activity at baseline and the risk of new onset LBP 12 months subsequently. ${ }^{15}$

In summary, the evidence relating to lifestyle factors is unclear. Although a number of authors have shown consistent cross sectional associations between LBP and physical activity, there is little consistent evidence from prospective studies to suggest that physical activity is a risk factor for future LBP. Similarly, although the cross sectional associations between sedentary activity and LBP may appear strong — with a convincing dose-risk relation-more recent longitudinal results would suggest that the high levels of sedentary activity in previous studies might have been consequences of LBP, rather than risk factors for it, and there is little evidence that prior sedentary activity is a risk factor for future LBP onset.

\section{Mechanical load}

Despite much subjective and anecdotal evidence that carrying heavy schoolbags "causes" LBP, there is actually very little epidemiological evidence examining the relation. Gunzburg et al showed that children who found their schoolbags to be heavy experienced a $60 \%$ increase in the odds of LBP. ${ }^{37}$ Similarly, other authors have shown an increase in the occurrence of LBP associated with the perception of schoolbag heaviness..$^{35}$ Using a more objective assessment, 
Watson et al collected data on actual schoolbag weight over a five day period and computed an average daily mechanical load. These authors found that children with the heaviest loads (6.4-18 kg per day) were no more likely to report LBP than children with the lightest loads $(<3.4 \mathrm{~kg}) .^{29}$

Viry et al show a doubling in the odds of LBP associated with a relative schoolbag weight (bag weight divided by body weight) of $>20 \%{ }^{10}$ In contrast, however, some have shown no such relation, ${ }^{13}$ and others have shown a significant trend, suggesting that the higher the relative bag weight, the lesser the odds of LBP: Watson et al reported a $40 \%$ decrease in the odds of LBP in children carrying $>14 \%$ of their body weight, compared to those carrying $<7 \%{ }^{29}$

The majority of studies published to date have been cross sectional in design. However, Jones et al followed up 933 children who were known to have been free of LBP at baseline. These authors showed that schoolbag weight at baseline was not associated with the risk of LBP at follow up: children carrying loads of 6.4-18 kg experienced no significant increase in risk compared to those carrying $<3.4 \mathrm{~kg}$ (relative risk $1.2 ; 95 \%$ confidence interval 0.7 to 2.1 ). ${ }^{15}$ Similarly, no association was found for relative schoolbag weight, although a small proportion of children with the heaviest mechanical exposures (in terms of load and duration carried) did show a small increase in risk.

In summary, the evidence to date does not suggest that mechanical load is an important cause of back pain in children across the range of schoolbag weights commonly carried to school. Future prospective studies, however, can usefully determine the risk associated with specific weights, and duration and method of carriage.

\section{Psychological factors and the social environment}

In children, the majority of aetiological studies on LBP have focused on mechanical and/or lifestyle factors. In the last decade, however, following a similar shift in studies of LBP in adults, $^{39}{ }^{40}$ a number of authors have examined the role of psychological and psychosocial factors in the epidemiology of LBP in childhood.

Balagué et al show, cross sectionally, that children with a high negative affect score were more likely to report a history of LBP than other children; whereas, a low positive affect score was associated with a decreased reporting of symptoms. ${ }^{6}$ Brattberg also reports an association between LBP and a number of psychosocial factors. ${ }^{16}$ The author reports that the odds of reporting LBP are two or three times greater in those with several negative psychosocial experiences. In addition, others have shown that children reporting conduct and emotional problems were twice as likely to report LBP than other children. ${ }^{29}$ Vikat et al showed a doubling in the odds of LBP in children who reported that they suffered from one psychosomatic symptom per week, compared to children who reported none, ${ }^{41}$ and this relation increased with increasing number of symptoms. Further, others have reported that children with other musculoskeletal pain symptoms not only had more emotional and behavioural problems than other children, but also reported an increased occurrence of depressive symptoms and sleep problems. ${ }^{42}$

Croft et al showed that in adults free of LBP at baseline, individuals with higher levels of anxiety and depression were more likely to report an episode of LBP in the subsequent 12 months than other individuals, ${ }^{40}$ and Papageorgiou et al showed that workplace dissatisfaction was also associated with an increase in new episodes of LBP. ${ }^{39}$ In children, however, little prospective work has been carried out. Jones et al followed up the cohort of Watson et al, ${ }^{29}$ and reported that conduct and emotional problems, in addition to the occurrence of other somatic symptoms (headache, abdominal pain), were significantly predictive of new onset LBP 12 months subsequently. ${ }^{15}$ Further, on multivariable analysis, these authors showed that behavioural characteristics and prior somatic symptoms were independently predictive of LBP at follow up (see table 1). In addition, these authors have subsequently shown that these factors are not only associated with an increased risk of LBP, but are also predictive of the onset of other musculoskeletal pain symptoms. ${ }^{43}$

In summary, there is good evidence that children with LBP are more likely to report negative psychosocial experiences, and there is some evidence to support the hypothesis that such negative experiences predict those at high risk of future onset.

\section{DOES LBP IN CHILDHOOD PREDISPOSE TO LBP IN ADULTHOOD?}

Adolescent LBP is not restricted to single and rare episodes. Several authors have shown that at least one third of children

\begin{tabular}{|c|c|c|c|}
\hline & \multicolumn{2}{|c|}{ New onset LBP } & \multirow[b]{2}{*}{ Relative risk $(95 \% \mathrm{Cl})$} \\
\hline & Yes & No & \\
\hline \multicolumn{4}{|l|}{ Age (years) } \\
\hline 11 & $19(12.5 \%)$ & 133 & 1.0 \\
\hline 12 & $61(1630 \%)$ & 321 & $1.6(0.9$ to 2.8$)$ \\
\hline 13 & $67(23.8 \%)$ & 214 & $2.1(1.1$ to 3.8$)$ \\
\hline 14 & $21(24.1 \%)$ & 66 & $2.7(1.4$ to 5.5$)$ \\
\hline \multicolumn{4}{|l|}{ Sex } \\
\hline Male & $72(16.9 \%)$ & 353 & 1.0 \\
\hline Female & $96(20.1 \%)$ & 382 & $1.4(0.97$ to 2.0$)$ \\
\hline \multicolumn{4}{|c|}{ Conduct problems } \\
\hline Low & $43(12.5 \%)$ & 302 & 1.0 \\
\hline Medium & $72(19.6 \%)$ & 295 & $1.6(1.1$ to 2.4$)$ \\
\hline High & $52(28.7 \%)$ & 129 & $1.9(1.2$ to 3.1$)$ \\
\hline \multicolumn{4}{|c|}{ Sporting activity (past week) } \\
\hline $0-100 \mathrm{~min}$ & $40(16.1 \%)$ & 209 & 1.0 \\
\hline $120-160 \mathrm{~min}$ & $36(22.8 \%)$ & 122 & $1.9(1.1$ to 3.3$)$ \\
\hline $180-220 \mathrm{~min}$ & $18(11.0 \%)$ & 145 & $1.0(0.6$ to 1.9$)$ \\
\hline $240-340 \mathrm{~min}$ & $32(20.9 \%)$ & 121 & $1.8(1.1$ to 3.2$)$ \\
\hline$\geqslant 360 \mathrm{~min}$ & $42(23.3 \%)$ & 138 & $2.3(1.3$ to 3.9$)$ \\
\hline \multicolumn{4}{|c|}{ Abdominal pain (days in past month) } \\
\hline None & $69(15.2 \%)$ & 385 & 1.0 \\
\hline $1-7$ days & $75(21.0 \%)$ & 283 & $1.3(0.9$ to 1.9$)$ \\
\hline$>7$ days & $20(27.0 \%)$ & 54 & $1.9(1.1$ to 3.4$)$ \\
\hline
\end{tabular}


with LBP have recurrent episodes. ${ }^{78}{ }^{10}$ Further, although very few longitudinal studies exist, Harreby et al showed that schoolchildren reporting LBP had an increased risk of having back pain 25 years subsequently. ${ }^{19}$ In contrast, in a 13 year follow up study of 335 children aged 8-17 years, reporting of back pain at recruitment did not predict back pain at follow up, but did predict the reporting of pain (generally) in adulthood ${ }^{44}$ Studies of other pain syndromes in childhood, such as abdominal pain or headache, on which there is more data, show consistently that there is a future risk of either the specific pain syndrome, medically unexplained syndromes, or adverse psychological outcomes. ${ }^{45-47}$

\section{CONCLUSIONS}

In summary, LBP in children and adolescents, as in adults, is a common condition: some have shown a lifetime prevalence as high as $70-80 \%$ by 20 years of age. In addition, several studies have calculated new onset rates of around $20 \%$ over a 1-2 year period. Pain prevalence increases with age and is higher in girls than boys. Although many children report certain limitations to daily activities as a result of their pain, health service consultation is low, and serious disability and hospitalisation is rare. For the majority of children, LBP is non-specific and self-limiting, and studies have shown that common imaging techniques are poorly able to discriminate between children with, and those without, LBP. Thus, in the minority of cases that do present to primary care, an organic cause is seldom found.

A number of studies have shown an association between physical lifestyle and LBP, although most studies have been cross sectional in design and are, therefore, unable to examine the temporal nature of any such relations. Prospective studies, however, have been unable to show any consistent evidence suggesting an increase in the risk of LBP associated with prior levels of physical or sedentary activity. ${ }^{15} 23$ Similarly, although several studies, but not all, have shown a cross sectional association between high mechanical load and LBP, more recent longitudinal studies have shown that heavy schoolbag weight is not associated with an increase in the risk of future LBP. In contrast, there is strong evidence highlighting the role of psychosocial and behavioural factors. A number of authors have shown strong cross sectional associations between adverse psychological or psychosocial factors and the occurrence of LBP, and others have shown that these factors, in the absence of LBP, significantly predict the future onset of symptoms.

In summary, there are currently few large scale prospective studies of the epidemiology of LBP in childhood. However, those that exist are providing increasing evidence that psychological and psychosocial factors play an important role in the aetiology of LBP, at least in the short term. Juvenile LBP appears to be, on the whole, mild and nonspecific, and there is a paucity of research focusing on the persistence of symptoms. Further studies are needed to examine the role of potential risk factors in the longer termparticularly psychological and social factors.

\section{Authors' affiliations}

G T Jones, G J Macfarlane, ARC Epidemiology Unit and The Unit of Chronic Disease Epidemiology, Division of Epidemiology and Health Sciences, University of Manchester, UK

Gareth T Jones is funded by the Arthritis Research Campaign (ARC), Chesterfield, UK

Competing interests: none declared

\section{REFERENCES}

1 Walker BF. The prevalence of low back pain: a systematic review of the literature from 1966 to 1998. J Spinal Disord 2000;13:205-17.
2 McCormick A. Morbidity statistics from general practice: fourth national study 1991-92/a study carried out by the Royal College of General Practitioners, the Office of Population Censuses and Surveys, and the Department of Health. London: HMSO, 1995.

3 Papageorgiou AC, Croft PR, Ferry S, et al. Estimating the prevalence of low back pain in the general population. Evidence from the South Manchester Back Pain Survey. Spine 1995;20:1889-94.

4 Papageorgiou AC, Croft PR, Thomas E, et al. Influence of previous pain experience on the episode incidence of low back pain: results from the South Manchester Back Pain Study. Pain 1996;66:181-5.

5 Watson KD, Papageorgiou AC, Jones GT, et al. Low back pain in schoolchildren: occurrence and characteristics. Pain 2002;97:87-92.

6 Balague F, Skovron ML, Nordin M, et al. Low back pain in school children: a study of familial and psychological factors. Spine 1995;20:1265-70.

7 Salminen JJ, Pentti J, Terho P. Low back pain and disability in 14-year-old schoolchildren. Acta Paediatr 1992;81:1035-9.

8 Taimela S, Kujala UM, Salminen JJ, et al. The prevalence of low back pain among children and adolescents: a nationwide, cohort-based questionnaire survey in Finland. Spine 1997;22:1132-6

9 Burton AK, Clarke RD, McClune TD, et al. The natural history of low back pain in adolescents. Spine 1996;21:2323-8.

10 Viry P, Creveuil C, Marcelli C. Nonspecific back pain in children. A search for associated factors in 14-year-old schoolchildren. Rev Rhum Engl Ed 1999;66:381-8.

11 Troussier B, Marchou-Lopez S, Pironneau S, et al. Back pain and spinal alignment abnormalities in schoolchildren. Rev Rhum Engl Ed 1999:66:370-80.

12 Brattberg G, Wickman V. Prevalence of back pain and headache in Swedish school children: a questionnaire survey. The Pain Clinic 1992;5:211-20.

13 Grimmer K, Williams M. Gender-age environmental associates of adolescent low back pain. Appl Ergon 2000;31:343-60.

14 Troussier B, Davoine P, de Gaudemaris R, et al. Back pain in school children. A study among 1178 pupils. Scand J Rehabil Med 1994;26:143-6.

15 Jones GT, Watson KD, Silman AJ, et al. Predictors of low back pain in British schoolchildren: a population-based prospective cohort study. Pediatrics 2003;111:822-8.

16 Brattberg G. The incidence of back pain and headaches among Swedish school children. Qual Life Res 1994;3:S27-31

17 Olsen TL, Anderson RL, Dearwater SR, et al. The epidemiology of low back pain in an adolescent population. Am J Public Health 1992;82:606-8.

18 Turner PG, Green JH, Galasko CS. Back pain in childhood. Spine 1989;14:812-14.

19 Harreby M, Neergaard K, Hesselsoe G, et al. Are radiologic changes in the thoracic and lumbar spine of adolescents risk factors for low back pain in adults? A 25-year prospective cohort study of 640 school children. Spine 1995;20:2298-302.

20 Tertti MO, Salminen JJ, Paajanen HE, et al. Low-back pain and disk degeneration in children: a case-control MR imaging study. Radiology $1991 ; 180: 503-7$

21 Fairbank JCT, Pynsent PB, van Poortvliet JA, et al. Influence of anthropometric factors and joint laxity in the incidence of adolescent back pain. Spine 1984;9:461-3.

22 Nissinen M, Heliövaara M, Seitsamo J, et al. Anthropometric measurements and the incidence of low back pain in a cohort of pubertal children. Spine 1994; 19:1367-70.

23 Salminen JJ, Erkintalo $M$, Laine $M$, et al. Low back pain in the young. A prospective three-year follow-up study of subjects with and without low back pain. Spine 1995;20:2101-7.

24 Salminen JJ, Maki P, Oksanen A, et al. Spinal mobility and trunk muscle strength in 15-year-old schoolchildren with and without low-back pain. Spine 1992;17:405-11.

25 Kujala UM, Taimela S, Oksanen A, et al. Lumbar mobility and low back pain during adolescence. A longitudinal three-year follow-up study in athletes and controls. Am J Sports Med 1997;25:363-8.

26 Harvey J, Tanner S. Low back pain in young athletes. A practical approach. Sports Med 1991; 12:394-406

27 Feldman DE, Shrier I, Rossignol M, et al. Risk factors for the development of low back pain in adolescence. Am J Epidemiol 2001;154:30-6.

27a Balague F, Damidot P, Nordin M, et al. Cross-sectional study of the isokinetic muscle trunk strength among school children. Spine 1993; 18:1199-205.

28 Harreby $M$, Nygaard B, Jessen T, et al. Risk factors for low back pain in a cohort of 1389 Danish school children: an epidemiologic study. Eur Spine J 1999;8:444-50.

29 Watson KD, Papageorgiou AC, Jones GT, et al. Low back pain in schoolchildren: the role of mechanical and psychosocial factors. Arch Dis Child 2003;88:12-17.

30 Duggleby T, Kumar S. Epidemiology of juvenile low back pain: a review. Disabil Rehabil 1997;19:505-12.

31 McMeeken J, Tully E, Stillman B, et al. The experience of back pain in young Australians. Man Ther $2001 ; 6: 213-20$.

32 Sward L, Eriksson B, Peterson L. Anthropometric characteristics, passive hip flexion, and spinal mobility in relation to back pain in athletes. Spine 1990;15:376-82.

33 Salminen JJ. The adolescent back. A field survey of 370 Finnish schoolchildren. Acta Paediatr Scand Suppl 1984;315:1-122.

34 Sjolie AN. Access to pedestrian roads, daily activities, and physical performance of adolescents. Spine 2000;25:1965-72.

35 Szpalski M, Gunzburg R, Balague F, et al. A 2-year prospective longitudinal study on low back pain in primary school children. Eur Spine $J$ 2002;11:459-64. 
36 Balague F, Dutoit G, Waldburger M. Low back pain in schoolchildren: an epidemiological study. Scandinavian Journal of Rehabilative Medicine 1988;20:175-9.

37 Gunzburg R, Balague F, Nordin M, et al. Low back pain in a population of school children. Eur Spine J 1999:8:439-43.

38 Negrini S, Carabalona R, Pinochi G, et al. Backpack and back pain in schoolchildren: is there a direct relationship? J Bone Joint Surg Am 1998;80B:247.

39 Papageorgiou AC, Macfarlane GJ, Thomas E, et al. Psychosocial factors in the workplace-do they predict new episodes of low back pain? Evidence from the South Manchester Back Pain Study. Spine 1997;22:1137-42.

40 Croft PR, Papageorgiou AC, Ferry S, et al. Psychologic distress and low back pain. Evidence from a prospective study in the general population. Spine 1995:20:2731-7.

41 Vikat A, Rimpela M, Salminen JJ, et al. Neck or shoulder pain and low back pain in Finnish adolescents. Scand J Public Health 2000;28: 164-73.
42 Mikkelsson M, Sourander A, Piha J, et al. Psychiatric symptoms in preadolescents with musculoskeletal pain and fibromyalgia. Pediatrics 1997; 100:220-7.

43 Jones GT, Silman AJ, Macfarlane GJ. Predicting the onset of widespread body pain among children. Arthritis Rheum 2003;48:2615-21.

44 Brattberg G. Do pain problems in young school children persist into early adulthood? A 13-year follow-up. European Journal of Pain: Eip 2004;8:187-99.

45 Fearon $\mathbf{P}$, Hotopf $M$. Relation between headache in childhood and physical and psychiatric symptoms in adulthood: national birth cohort study. BMJ 2001;322: 1145.

46 Hotopf M, Carr S, Mayou R, et al. Why do children have chronic abdominal pain, and what happens to them when they grow up? Population based cohort study. BMJ 1998:316:1196-200.

47 Hotopf M, Wilson-Jones C, Mayou R, et al. Childhood predictors of adult medically unexplained hospitalisations. Results from a national birth cohort study. Br J Psychiatry 2000;176:273-80.

\section{IMAGES IN PAEDIATRICS}

\section{Acute haemorrhagic oedema of infancy}

doi: $10.1136 /$ adc. 2004.060632

A previously healthy 12 month old girl presented with a one week history of coryzal symptoms and a 24 hour history of an unusual rash. Initially, her right ear had appeared bruised, but over 12 hours both ears became progressively more swollen, protruding, and discoloured (figs 1 and 2 ). The rash on her limbs and face was initially papular, then the lesions increased in number and size, becoming annular and purpuric (fig 3). There was some swelling of her top lip and a right subconjunctival haemorrhage. There was no respiratory difficulty, abdominal discomfort, or joint pain. She was normotensive and urinalysis was negative. Full blood count and clotting screen were normal. There was no further progression of the rash, but 72 hours later she developed tense oedema of both hands and feet. The rash and oedema resolved completely within two weeks.

This presentation is typical of acute haemorrhagic oedema of infancy, which was first described in 1913, ${ }^{1}$ but has been rarely reported in the English language literature. ${ }^{2}$ It is characterised by the sudden appearance of sharply demarcated, annular, purpuric lesions, limited almost entirely to the face and limbs and often accompanied by oedema and low grade fever. It is frequently preceded by respiratory tract infection, drug intake, or vaccination, and typically affects children between 4 and 24 months of age. ${ }^{3}$ Systemic symptoms such as abdominal pain, gastrointestinal bleeding, arthritis, and nephritis are rarely reported. Spontaneous and complete resolution occurs within one to three weeks although recurrences are not uncommon. There is no specific therapy. Systemic corticosteroids do not alter the disease course. The histological findings in skin biopsy specimens are those of a leucocytoclastic vasculitis. IgA

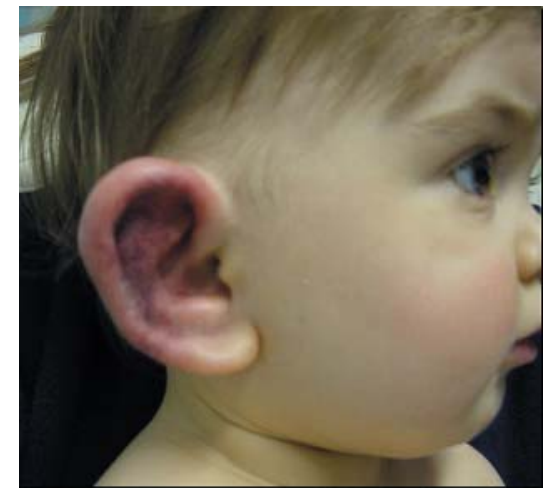

Figure 1 Haemorrhagic swelling of right ear.

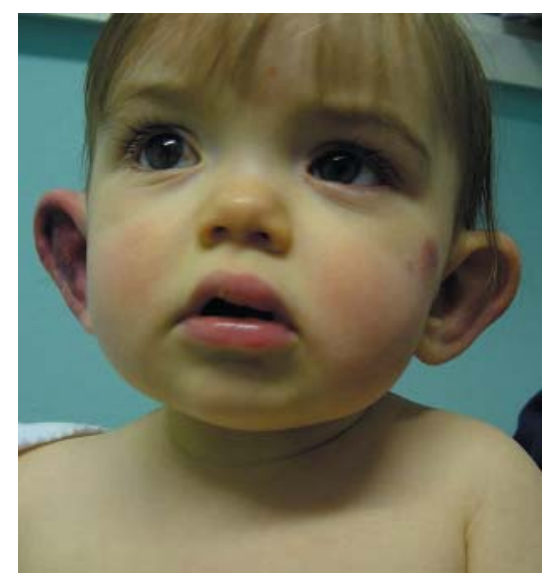

Figure 2 Prominent swelling and discoloration of both ears, swollen upper lip, a right subconjunctival haemorrhage, and a purpuric lesion on the left cheek.

deposition is observed in about one third of specimens.

Acute haemorrhagic oedema of infancy may be considered a mild variant of Henoch-Schönlein purpura, but recognising it as a distinct clinical entity allows an appropriate prognosis

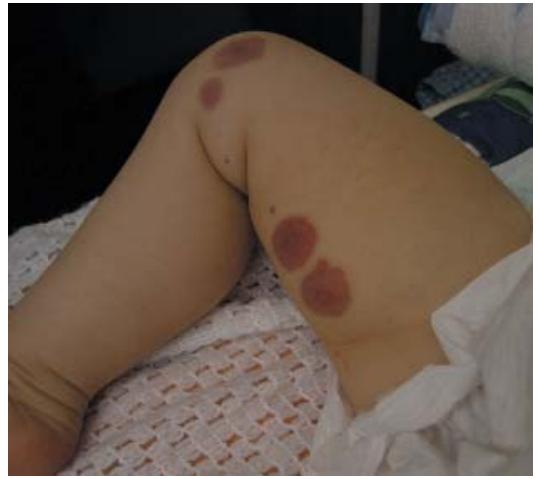

Figure 3 Typical annular purpuric lesions and smaller papular lesions on the right leg.

to be made for this generally benign disease of infants. ${ }^{23}$

C M McDougall

Department of Child Health, University of Aberdeen, Royal Aberdeen Children's Hospital,

Westburn Road, Aberdeen AB25 2ZG, UK

S K Ismail

Royal Aberdeen Children's Hospital, UK

A Ormerod

Aberdeen Royal Infirmary, UK

Correspondence to: $\operatorname{Dr}$ CM McDougall, Department of Child Health, University of Aberdeen, Royal Aberdeen Children's Hospital, Westburn Road, Aberdeen AB25 2ZG, UK; c.mcdougall@abdn.ac.uk

Parental consent has been obtained for figures 1-3

\section{References}

1 Snow IM. Purpura, urticaria and angioneurotic edema of the hands and feet in a nursing baby. JAMA 1913;61:18-19.

2 Saraclar Y, Tinaztepe K, Adalioğlu G, et al. Acute hemorrhagic edema of infancy (AHEI) - a variant of Henoch-Schönlein purpura or a distinct clinical entity? J Allergy Clin Immunol 1990;86:473-83.

3 Legrain V, Lejean S, Taieb A, et al. Infantile acute hemorrhagic edema of the skin: study of ten cases. J Am Acad Dermatol 1991;24:17-22. 